\title{
A study on supplier and buyer coordination on pharma supply chain
}

\author{
T. Praveen ${ }^{1}$ and V. V. Suraj ${ }^{2 *}$ \\ ${ }^{1 \& 2}$ Ramaiah Institute of Management, Bangalore, India
}

DOI: http://doi.org/10.52814/PJMA.2021.1102

ARTICLE TYPE: Research paper

ARTICLE HISTORY: Submitted: January 2021, Revisions: March 2021, Accepted: March 2021

HOW TO CITE: Praveen, T. and Suraj, V. V. (2021). A study on supplier and buyer coordination on pharma supply chain. Prayukti - Journal of Management Applications, Vol. 1, Issue 1, pp. 09-18.

*Corresponding author e-mail: velagapudisuraj@gmail.com

\begin{abstract}
This paper explores the coordination between Buyer and Supply in the supply chain of pharmaceuticals. As a competitive market, the key downside for the pharma supply chain is sufficient assessment and improper supplier selection. 114 wholesalers and retailers in the pharma supply chain collected sample data. A questionnaire was circulated to assess the preference of the local supply chain of pharmaceuticals in selecting the supplier. The primary emphasis on delivery, quality, expense, delivery, flexibility, environmental factors, information and communication and technology is on supplier selection criteria. Many businesses depend on partnerships with partners that are tightly cooperative. This research illustrates requirements in the pharmaceutical supply chain for supplier and buyer evaluation that are useful for serving, sharing knowledge and creating new and evolving strategies for operating the supply chain in changing economies. The results will assist the supply chain of pharmaceuticals in determining their suppliers.
\end{abstract}

KEYWORDS: Buyers, Suppliers, Supply Chain, Pharma Industry.

\section{INTRODUCTION}

Indian pharmaceutical companies develop, produces, distributes various medicines or drugs to the market. Pricing and costs associated which were major concern for growth of the company. As some companies depends up on one-third of revenue towards the supply chain management some of the functions like transportation and infrastructure. Industry focuses strictly on the patents, safety and testing of medicines manufacturing and marketing. Supply chain management expects lower expenses and increasing sales. In India SCM cost is more which is $13 \%$ of countries gross domestic product.

Indian pharmaceutical industry is about to gain $15 \%$ to $20 \%$ CAGR to $\$ 74$ billion over next decade. Some of the top companies like Sun pharmaceuticals, lupin ltd, Cipla, Novartis are partly foreign owned companies which contribute to economic growth. While customer purchasing and higher spending in healthcare were increasing since few years. 
While supply chain activities like sourcing, procurement and logistics integrated in recent business. companies focus on effective utilization of resources, capacity and inventory in changing environment.

Logistics services plays a key role in delivering right medicine at right time with better quality. Some logistics players include suppliers, wholesalers and retailers which transfer finished products to end user. Manufacturing, operations, marketing and product design play a significant role in business growth. In today's highly competitive climate, the assessment and selection of suppliers has become a primary focus area of concern for purchasing managers as the cost of raw materials purchased for production considers that a higher percentage of the overall cost of finished goods is high for organization. To get the supplier's best offer. In achieving the objectives of supply management, suppliers play an important role.

Supplier selection is a downside that cannot be easy for the ability of the department to contract the best supplier for a company that contributes to substantial cost savings due to the different drugs available to society, it cannot be overemphasized to perform supply chain management research in the pharmaceutical industry. Maintaining long-term prove more advantage for organization than using power over trade to get maximum value in the short run. In general, there has been lack of field research on the distribution and power in supply chain and supply networks.

As $13 \%$ of total cost and medicines reduces the need for more expensive treatment and important aspect of the patient's experience from health service. The supplier investigation within wholesalers and retailers an alternative source of supply for pharma with in supply chain and provide direct competition for buyer and wholesaler on the principle that products can be obtain at low cost.

The pharmaceutical industry is characterized as a combination of different operations and processes involved in drug discovery, development and manufacturing. Mainly focused on the supplier selection and factors affecting the supplier selection to mitigate the risk involved in regard and improve their market share, increase profit and achieve the competitive advantage and step forward by standardization and improve for customer expectation.

The supplier outside the organization have been facing the variety of options and selecting the source of supply increasing the commercial competition in global market to get more attention to optimizing their processes in various aspects which include supplier selection. Various decision making in the outsourcing to select the alternative among available suppliers which can meet all of the outsourced process needs in the best possible way. The creation and management of productive partnerships at all points in the supply chain is becoming an important factor in the success of companies.

High industrial volatility reflects rapid consumer demand swings and volatile industry trends. The multiple diversity of environmental companies, facing market uncertainty and diversity, encourages retailers to strengthen flexible partnerships with multiple channel partners to cope with unforeseen market demands and reduce vendor dependence. Higher profitability is achieved by companies engaged in long-term relationships with their customers, and the transactional approach (Kalwani and narayandas 1995) and maloni (2000) found that good purchaser and supplier collaboration had a positive impact on supplier performance.

Coordination of the supply chain is a systematic, strategic, objective, process-based approach to integrating multiple processes in order to establish specific and individualized sources of consumer value (Siyu, 2018). Coordination between buyer and seller addresses consumer needs more efficiently and effectively in the marketplace (Oke and Olhager 2016). In order to accomplish the project initiative, suppliers play an important role (Krichanchai and Maccarthy, 2017).

The key to running pharmaceutical firm is not managing functions but to manage supply chain processes and improve the quality of distribution and better price for customer 
satisfaction. The purpose of research was to explore the distribution power in pharma supply chain and examining its relationship with suppliers.

Fig. 1: Supply Chain Coordination

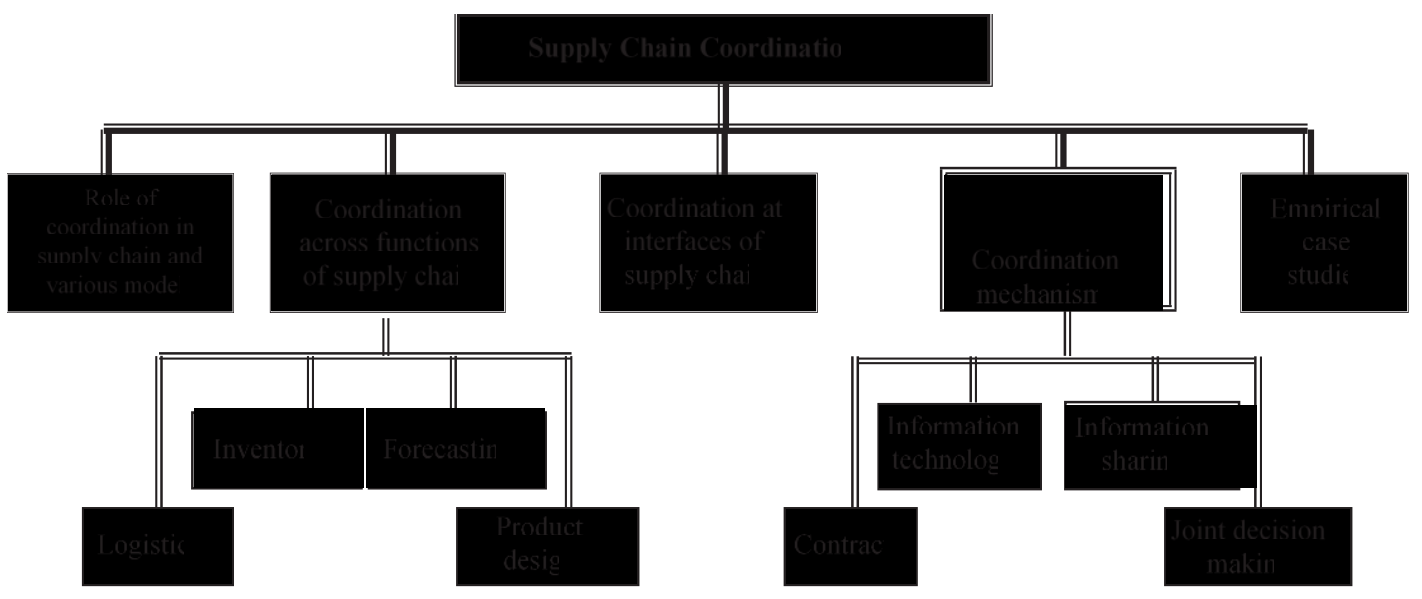

\section{LITERATURE REVIEW}

Will the preference of suppliers play an important role for purchasers in the supply chain of pharmaceuticals? The output of suppliers plays a key role in the market. There some ways of selection which help buyer to examine the selection process. Buyer select the supplier based on the requirement factor and performance.

A review in Malaysia on manufacturing industry criteria for supplier selection. Suppliers suggest various changes depending on the success of local clients. In the selection process, he determines the main criterion, selection criteria and other variables to be initiated by the buyer. A smaller number of respondents chose to retain a reliable local supplier based on the respondents. Most consumers regard cost and service as a selection process until suppliers are chosen (Sim et al., 2020).

AHP Strategy for Supplier Assessment and Selection at a Pharmaceutical Manufacturing Firm in Ghana. The analysis takes into account the importance of quality, expense, reliability, compliance with regulations, risk, financial position and supplier profile for the choice of suppliers. It makes it simpler for the customer to evaluate, rate and pick the supplier in a timely and favorable way. He illustrated essential criteria such as consistency, price and reliability/capacity for the selection of the best supplier (Asamoah et al., 2012).

The Pharmaceutical Supply Chain Buyer-Supplier Coordination Background. Transactional cost theory, environmental uncertainty was used at three distinct levels, such as transactional, operational and strategic, to understand background influence using transaction cost analysis in the pharma supply chain based on asset specificity (Jambulingam and Kathuria, 2020).

Coordination and profit-sharing under credit option between a manufacturer and a buyer with target profit. The study describes the coordination of buyer vendor for credit option in such a way that both parties can divide equitably according to profit targets Knowledge that can have a negative effect is shared by both the customer and the supplier. The supply chain can also be misloaded by the manufacturer's division of benefit under imperfect sharing of knowledge (Sarmah et al., 2006).

In India, a comparative study of multi-criteria decision-making processes tests the efficiency of healthcare supply chains. The efficiency of the supply chain stands as a crucial decision factor for better profitability of companies. Supply Chain Management (SCM) includes all financial targets related to the balance between demand and supply. He gathered the opinions of experts on the understanding of trade between supplier and consumer (Biswas, 2020). 
Recently, Musnaini et al. (2020) conducted research predictors for the Indonesian Pharmaceuticals industry's company output and supply chain proof. The study explains the agility of the supply chain, integration, capacity plays a major role in company success. Developing different supply chain strategies leads to a changing global economy.

Zhixiang (2004) conducted an investigation into the efficiency of supplier/buyer cooperation in Chinese firms. The survey describes a rapidly rising economy that has given greater importance to cooperating and collaborating with pharma supply chain partners. Based on distribution, efficiency and responsiveness, which creates upward sharing of trend data to minimize inventory and expense.

Wang (2004) presented the management of supply chain buyer-supplier relationships in automotive and telecommunications supply chain case studies.Research shows that the interaction with market and consumer needs is the best way to strengthen the relationship between suppliers. The customer and supplier relationship moves with the pacing of the product life cycle. Companies use different strategic stages of the relationship between buyer and supplier.

Bigliardi and Bottani (2014) discussed a literature review and pilot study among Italian manufacturing firms on supply chain performance measurement. The study explains the difficulties in the coordination of the supply chain that are mismatch in batch sizes, mismatch in production set-up times, independent cost assessment of activities and processes, overlapping priorities, independent replenishment, lack of independent replenishment.

Hsiao et al.(2005) addressed the effect on the efficiency of the supply chain of the buyer-supplier relationship and purchasing process, a conceptual structure study conducted on the basis of two factors influencing existing retail supply chains, alignment of supplierbuyer and processes related to the cultural climate. Performance-based on the supply chain.

Chatziaslan et al. (2005) conducted analysis of power in buyer supplier relationships in the Pharmaceutical supply network in the UK National health service and international market. He illustrated on efficient procurement, distribution and safe handling of medicines must be high as implement pharmaceuticals in the right time and place and at a reasonable price must be key to guide patients and improve efficiency.

Sabbaghi and Allahyari (2019) presented a model of supplier selection that emphasizes project risk management in the pharmaceutical industry in drug development. $\mathrm{He}$ defined eight phases based on 30 secondary data implemented by the top supplier on efficiency, flexibility, distribution, technology, information and communication systems, costs and experience using the TOPSIS techniques.

Khurrum and Bhatta (2003) offered observations relevant to the literature review of Supplier Selection issue methodology. He divided the collection of suppliers into three categories: large contributors, medium contributors and low contributors. Selection and assessment investigated by conception, case study, parameters, literature review, mathematical models and methodology became the basis of literature.

Ware et al. (2012) identified a state of the art analysis on the issue of supplier selection. The rivalry is between companies and suppliers. Buyers favor quick delivery, excellent service environmental factors and product quality enhancement with increased service level. Pricing structure, distribution, lead time are used for production to excel in market fundamental parameters.

Alzoubi et al.(2020) conducted research on sustainable strategies for the supply chain and the effect of supply chain cooperation on strategic requirements and mediating positions. He clarified that the supply chain was faced with a lot of pressure caused by environmental factors. A questionnaire was distributed to the top manager in the distribution for subsequent actions.

Yao and Chun (2003) identified the coordination of the replenishment with the buyer and supplier in the integrated supply chain. Research has been done to reduce the expense of the producer in comparison to the high costs paid by the customer. Centered on the coordination of the cost curve between buyer and seller. As the collaboration of suppliers does not occur, the supply chain phase leads to different issues. 
The scale, challenges and issues in the Indian pharma supply chain were defined by Meghana Vyas. He defines the success of the supply chain in the industry as constructive. Implement different ideas, extend the life cycle of the product and increase performance, and use knowledge for improved customer service.

Fernando (2020) describes a systematic literature analysis of the main strategic issues of SCM's pharmaceutical industry. The choice of supplier plays a major role in the development of new goods. Some countries, such as China and the USA, have led the supply chain growth, and improvement in networking and competitiveness is a major problem.

SCM's effect on quality management is defined by Yanya and Mahamat (2020). In order to improve the coordination between customer and supplier, the study sets out the relationship between quality control. There was no moderation between learning and economic conditions observed. The study explains the difficulties and problems faced by small and medium-sized businesses due to financial support and lack of financial support.

\section{STATEMENT OF PROBLEM}

Does supplier and buyer coordinate in the pharma supply chain? The study relates the key focus of supplier and buyer requirements like mutual agreement, resolving problems and decision making which are measurable improvement and perform through incentives. Firstly, the supplier has to analyze demand requirement of the buyer which are customer needs. To better monitor and increase the quality of distribution, define the members of the channel. Coordination of the supply chain is crucial in increasing product availability in the pharma supply chain, unlike other industries. Some of the factors which were important for buyer are quality, environmental terms, delivery, cost, information and communication, flexibility (supplier relationship), record, technology and supplier experience.

In the supplier point of view provide service support to the buyer in technical, fast response and improve relationship in pharma supply chain. Hence the present study focuses on buyer and supplier with respect to order qualifying and order winning criteria in pharma supply chain.

\section{OBJECTIVES OF THE STUDY}

- To know the factors which Increasing the importance between supplier and buyer context affects supply chain coordination.

- To know the factors regarding the supplier selection criteria

\section{HYPOTHESIS}

- $\mathbf{H a}_{\mathbf{a}}$ (Alternative Hypothesis): There is significant relationship among delivery, quality, cost, services and supplier relationship in pharma supply chain.

- Ho (Null Hypothesis): There is no significant relationship among delivery, quality, cost, services and supplier relationship in pharma supply chain.

- $\mathbf{H}_{\mathbf{a}}$ (Alternative Hypothesis): There is significant role of supplier coordination in order qualifying criteria and order winning criteria in pharma supply chain

- Ho (Null Hypothesis): There is no significant role of supplier coordination in order qualifying criteria and order winning criteria in pharma supply chain.

Order qualifying criteria based on cost, quality and delivery, Order winning criteria based on services and supplier relationship.

\section{RESEARCH METHODOLOGY}

Type of Research Design: Descriptive research. The empirical study describes the knowledge, viewpoint and hypothesis suggested by primary data collection to be tested and validated. Instead of collecting a large sample of a population quantification, qualitative study is a strategic and investigative mode as a target for deep data from a particular field. While the procurement and selection supplier is an important part of supply chain management to 
ensure that qualifying, selection and other selection criteria enable the customer to meet the selection criteria referred to as supplier selection criteria or order winner. While the buyer prefers based on better customer service, sales service, easily accessible, technical support and warranty. while good supplier help manufacturer to develop new product and quality improvement at less cost. A pharmacy representative who has been active in buying activities and familiar knowledge of the relationship with their wholesalers and retailers when they were asked to determine their suppliers filled out the questionnaire. The cooperation of the buyer and supplier was calculated on a formative scale and a reflective scale.

Population: - Pharma Supply Chain in Vijayawada. Precise investigation on pharma supply chain knowledge and worked on the hypothesis from an operational outlook.

Target Sample: - Retailer and Wholesalers of Pharmaceutical (professionals).

Sampling Method: - Non-Sampling. As a study, it is understood that responses are quicker and more cost-effective.

Data Sources: - Primary Sources. The method used for data collection were questionnaire followed by in-depth interviews. While some data is collected from pharma industry reports and research articles from google scholar were collected and reported.

Sampling Unit: - One town and AutoNagar Industrial Estate, Vijayawada

Sample Size: 114 professionals in Pharma Supply Chain.

Data Collection Method:

Primary Data: The methods used for data collection was questionnaire. The questionnaire was administered based on order winning criteria and order qualifying criteria which were main source for wholesalers and retailers based on some knowledge then only questionnaire was asked to fill up. The questionnaire was distributed in hand and through online google forms. After the receival of questionnaire few of the respondents were asked questions on their response to have an in-depth knowledge of the options.

Secondary Data: The company websites pharma industry yearly reports and research articles from Google scholar were collected and reported.

Data collection Tool: - Questionnaire. The questionnaire was administered to the technical or managerial background people. Before administering the questionnaire, the respondents were asked if they have knowledge and only questionnaire were distributed in hand and through online google forms.

Evaluating Data: - Editing and Coding by using SPSS 20 and MS Excel.

Techniques: - Correlation on order winning criteria and order qualifying criteria. Order qualifying criteria depends on cost, quality and delivery. Order winning criteria depends on services and supplier relationship.

\section{SCOPE OF THE STUDY}

The study will be conducted on order qualifying criteria and order winning criteria.

- Country: - India

- State: - Andhra Pradesh

- Duration: - 2 months

- Place: - Vijayawada 
- Product/ Services: - Pharmaceutical Supply Chain services

- Factors Considered for the Study

Based on the literature review and primary discussions with some of the professionals and with the pilot study of 15 personnel. These factors were finalized:

\begin{tabular}{|c|l|}
\hline \multicolumn{2}{|c|}{ Table 1: Factors considered for study } \\
\hline GROUP & \multicolumn{1}{|c|}{ REQUIREMENT } \\
\hline DELIVERY & $\begin{array}{l}\text { On time delivery, less lead time, reliable delivery, supplier distribution network, p } \\
\text { received type and good quality packaging. }\end{array}$ \\
\hline COST & $\begin{array}{l}\text { Lower transaction cost, reducing additional cost, free distribution/logistics and free } \\
\text { service after sales and Discount on bulk order and early payments. }\end{array}$ \\
\hline QUALITY & $\begin{array}{l}\text { Meeting expected standards and less rejection/returns, providing samples before } \\
\text { ordering, continuous improvement having mutual collaboration and authorized } \\
\text { certificates }\end{array}$ \\
\hline SERVICES & $\begin{array}{l}\text { Good after sales services, Technical support, Ability to interact with buyer, Insurance } \\
\text { and responsiveness }\end{array}$ \\
\hline $\begin{array}{c}\text { SUPPLIER } \\
\text { RELATIONSHIP }\end{array}$ & $\begin{array}{l}\text { Good responsibility, long term cooperation, Good personality, performance history, } \\
\text { Customer trade record }\end{array}$ \\
\hline \multicolumn{1}{|c|}{ Source: Author's analysis } \\
\hline
\end{tabular}

The above-mentioned factors were considered in the study and used for questionnaire to collect the data from the respondents. The factors were considered from the review literature from different articles and scope of study was related to retailers and wholesalers which are important for consumer view as well. Both the development and affects were studied to know the gap in the pharma supply chain.

\section{ANALYSIS}

This chapter consists of data analysis for testing the hypothesis considering the important factors with respect to order winning criteria and order qualifying criteria in pharma supply chain. The factors for the data analysis were derived from literature review and in-depth interview with exports in pilot study. Based on the important factors were derived which are cost, quality, delivery, flexibility, environment factors, services, supplier relationship were considered. The data for analysis was obtained through structured questionnaire. The data was converted into suitable form and following tests were performed.

Hypothesis 1: Significant relationship among delivery, quality, cost, services and supplier relationship in pharma supply chain.

\begin{tabular}{|c|c|c|c|c|c|c|}
\hline \multicolumn{7}{|c|}{ Correlations } \\
\hline & & DELIVERY & QUALITY & COST & $\begin{array}{l}\text { SUPPLIER } \\
\text { RELATION }\end{array}$ & SERVICES \\
\hline \multirow{3}{*}{$\begin{array}{l}\text { DELIV } \\
\text { ERY }\end{array}$} & Pearson Correlation & 1 & $.669^{* *}$ & $.696^{* *}$ & $.630^{* *}$ & $.729^{* *}$ \\
\hline & Sig. (2-tailed) & & .000 & .000 & .000 & .000 \\
\hline & $\mathrm{N}$ & 114 & 114 & 114 & 114 & 114 \\
\hline \multirow{3}{*}{$\begin{array}{l}\text { QUALI } \\
\text { TY }\end{array}$} & Pearson Correlation & $.669^{* *}$ & 1 & $.795^{* *}$ & $.626^{* *}$ & $.705^{* *}$ \\
\hline & Sig. (2-tailed) & .000 & & .000 & .000 & .000 \\
\hline & $\mathrm{N}$ & 114 & 114 & 114 & 114 & 114 \\
\hline \multirow[t]{3}{*}{ COST } & Pearson Correlation & $.696^{* *}$ & $.795^{* *}$ & 1 & $.671^{* *}$ & $.755^{* *}$ \\
\hline & Sig. (2-tailed) & .000 & .000 & & .000 & .000 \\
\hline & $\mathrm{N}$ & 114 & 114 & 114 & 114 & 114 \\
\hline \multirow{3}{*}{$\begin{array}{c}\text { RELAT } \\
\text { IONSH } \\
\text { IP }\end{array}$} & Pearson Correlation & $.630^{* *}$ & $.626^{* *}$ & $.671^{* *}$ & 1 & $.806^{* *}$ \\
\hline & Sig. (2-tailed) & .000 & .000 & .000 & & .000 \\
\hline & $\mathrm{N}$ & 114 & 114 & 114 & 114 & 114 \\
\hline \multirow{3}{*}{$\begin{array}{c}\text { SERVI } \\
\text { CES }\end{array}$} & Pearson Correlation & $.729^{* *}$ & $.705^{* *}$ & $.755^{* *}$ & $.806^{* *}$ & 1 \\
\hline & Sig. (2-tailed) & .000 & .000 & .000 & .000 & \\
\hline & $\mathrm{N}$ & 114 & 114 & 114 & 114 & 114 \\
\hline
\end{tabular}


**. Correlation is significant at the 0.01 level (2-tailed).

\section{DATA INFERENCE}

From the analysis, with respect to delivery relationship with quality is 0.669 . delivery with relation to cost is 0.696 . delivery with relation to supplier relationship is 0.630 , delivery with relation to services is 0.729 . Quality with relation to cost is 0.795 , quality with relation to supplier relationship is 0.626 . quality with relation to services is 0.705 . Cost with relation to supplier relationship is 0.671 , cost with relation to services is 0.755 . Therefore, from Pearson correlation significance value is less than 0.5. Therefore, alternative hypothesis is accepted. Hence there is significant relation with the delivery, cost, quality, services and supplier relationship.

HYPOTHESIS 2: Significant role of Supplier Coordination in Order Qualifying Criteria and Order Winning Criteria in Pharma Supply Chain.

\begin{tabular}{|c|c|c|}
\hline \multicolumn{3}{|c|}{ Table2: T-Test: Paired Two Sample for Means } \\
\hline & Variable 1 & Variable 2 \\
\hline Mean & 3.169298 & 3.159357 \\
\hline Variance & 0.629049 & 0.496753 \\
\hline Observations & 114 & 114 \\
\hline Pearson Correlation & 0.801824 & \\
\hline Hypothesized Mean Difference & 0 & \\
\hline Df & 113 & \\
\hline t Stat & 0.221638 & \\
\hline $\mathrm{P}(\mathrm{T}<=\mathrm{t})$ one-tail & 0.412498 & \\
\hline $\mathrm{t}$ Critical one-tail & 1.65845 & \\
\hline $\mathrm{P}(\mathrm{T}<=\mathrm{t})$ two-tail & 0.824996 & \\
\hline $\mathrm{t}$ Critical two-tail & 1.98118 & \\
\hline \multicolumn{2}{|c|}{ Source: Author's analysis } \\
\hline \multicolumn{2}{|c}{} \\
\hline
\end{tabular}

DATA INFERENCE: From the $\mathrm{P}=0.82$ study above, which is greater than 0.05 . A null hypothesis is thus accepted. There is no important distinction between the criteria for order winning and the criteria for order qualifying. This demonstrates that both the requirements for order winning and order qualifier selection are necessary for the choice of suppliers.

The objective of the study revolved around identifying the factors with respect to pharma supply chain that influence the knowledge of the order winning criteria and order qualifying criteria. Through literature review and in-depth interviews various important variables were derived which are associated with supply chain coordination. The correlation analysis was conducted and variables was categorized from cost, delivery, quality, flexibility, environment factors, services and supplier relationship. The first objective focuses on the identifying the relationship between the quality and delivery of service. From the analysis we conclude that there is strong positive significance difference between them in pharma supply chain. Meeting expected standards and less rejection/er returns, Good after sales service and ability to interact with buyer were more important while considering supplier selection.

The second objective focuses on the identifying the relationship between the order winning criteria and order qualifying criteria. While order winning criteria are cost, delivery and quality. Buyers prefer vendors that can offer better after-sales customer care, easy to test, technical support and product warranty, which are components of good customer service. Good suppliers help with long-term quality management, cost savings and increased delivery efficiency during the production of new products and processes. The supplier is not only a dealer, but also a business associate for the customers. Geographical places, economic status, record of success, business history and culture may be essential factors that could impact the supplier's credibility. 


\section{FINDINGS}

With respect to delivery relationship with quality is 66percent. delivery with relation to cost is 69.6percent. delivery with relation to supplier relationship is 63.0 percent, delivery with relation to services is 72.9 percent. Quality with relation to cost is 79.5 percent, quality with relation to supplier relationship is 62.6 percent. quality with relation to services is 70.5 percent. Cost with relation to supplier relationship is 67.1 percent, cost with relation to services is 75.5 percent. Therefore, from Pearson correlation significance value is less than 0.5. There is significant relation between cost, quality, services, supplier relationship and delivery. The above analysis $\mathrm{P}=0.82$ which is greater than 0.05 . Therefore, null hypothesis is accepted. There is no significant difference between order winning criteria and order qualifying criteria. This shows that order winning and order qualifier selection criteria both are important for the supplier selection.

\section{CONCLUSION}

Through literature review and in-depth interviews various important variables were derived which are associated with supply chain coordination. The correlation analysis was conducted and variables was categorized from cost, delivery, quality, flexibility, environment factors, services and supplier relationship. The first objective focuses on the identifying the relationship between the quality and delivery of service. From the analysis we conclude that there is strong positive significance difference between them in pharma supply chain. Meeting expected standards and less rejection/er returns, Good after sales service and ability to interact with buyer were more important while considering supplier selection. The second objective focuses on the identifying the relationship between the order winning criteria and order qualifying criteria. While order winning criteria are cost, delivery and quality. Buyer prefer the suppliers who can provide better customer service after sales service, easy assessable, technical support and warranty of product which are elements of good customer service. Good supplier helps during development of new products and process with long term quality improvement, cost reduction and enhance delivery performance. Supplier is not only a seller but more as business partner for the purchasers. Geographical locations, financial status, performance record, company background and culture can be important criteria which might affect the reputation of the supplier.

\section{SUGGESTION}

Wholesalers and Pharmacy must keep more focus on supply chain coordination to able to sustain in competitive environment with less cost. Firms considers various criteria's while selection of supplier but main focus is on cost and quality of service. If they were not up to mark leads to disqualify suppliers. Traditional based communication and information sharing plays a major role for development of supplier and buyer coordination. Most of the firms were trying to implement new strategies to decrease inventory cost to enhance the efficiency of buyer and supplier coordination. The pharmacies must focus on the wholesaler product requirement and implement loyalty program and offers. Supply chain coordination can achieve product availability to the patients at the right quality, right quantity, right time, right location and right price unlike other industries supply chain can impact the healthcare system.

\section{REFERENCES}

- Arshinder, Arun Kanda and Deshmukh, S. G. (2008). Supply chain coordination:Perspectives, empirical studies and research directions. Int J.Production Economics, 115, pp. 316-335.

- Asrini, M., Setyawati, Y., Kumalawati, L. and Fajariyah, N. A. (2020). Predictors of Firm Performance and Supply Chain: Evidence from Indonesian Pharmaceuticals Industry. Int. J Sup. Chain. Mgt Vol, 9(1), 1080. 
- B. Bigliardi and E.Bottani (2014) supply chain performance measurement a literature review and pilot study among Italian manufacturing companies. International Journal of engineering Science and Technology, Vol.6, NO.3, 2014, pp. 1-16.

- Biswas, S. (2020). Measuring performance of healthcare supply chains in India: A comparative analysis of multi-criteria decision-making methods. Decision Making: Applications in Management and Engineering, 3(2), pp. 162-189.

- Zhiciang, Chen (2004), Investigation of supplier/buyer coordination performance in Chinese companies. China national high technology Research and development Program (863) V. 11, No. 3, pp. 289-298.

- David, Asamoah, Jonathan Annam, Samuel, Nyarko (2012). AHP Approach for Supplier Evaluation and Selection in a Pharmaceutical Manufacturing Firm in Ghana. International Journal of Business and Management, Vol. 7, No.10.

- Detcharat Sumrit (2019), Supplier selection for vendor-managed inventory in healthcare using fuzzy multi-criteria decision-making approach. Decision Science Letters, 9, pp. 256.

- H. K. Sim and Mohamed K. Omar, W. C. Chee, N. T. Gan (2010). A Survey on supplier selection Criteria on the manufacturing industry in Malaysia. Researchgate/261876944.

- Kapoor, D., Vyas, R. B. and Dadarwal, D. (2018). An overview on pharmaceutical supply chain: a next step towards good manufacturing practice. Drug Designing \& Intellectual Properties International Journal, 1(2), 49-54.

- L. Chatziaslan, L.Breen, M Webster (2015). An Analysis of power in buyer-supplier relationships in the Pharmaceutical Supply Network in UK National Health Service and its Application to International Markets. Researchgate/276284650.

- M. Khurrum and S. Bhutta (2003). Supplier Selection Problem: Methodology Literature Review. Journal of International Information Management, Vol. 12, Iss. 2.

- Malek Mohammad Sabbaghi and Ahmad Allahyari (2020). A Supplier Selection Model Emphasizing the Risk Management in Drug Production in Pharmaceutical Industry. Technical Journal, pp. 111-120.

- Melody, J. Hsiao, Sharon Purchase and Shama Rahman (2005). The impact of buyersupplier relationship and purchasing process on the supply chain performance. Impgroup-journal.

- Muysinaliyev, A. and Aktamov, S. (2014). Supply chain management concepts: literature review. IOSR Journal of Business and Management, 15(6), pp. 60-66.

- Nilesh, R; Ware, S.P. Singh and D.K. Banwet (2012). Supplier selection problem: A state-of-the-art review. Management Science Letters, 1465-1490.

- Patil, Sanjaykumar Jagannath and Patil, Yogita Sanjaykumar (2019). Innovation in Supply Chain Management of Vegetables and Fruits in Maharashtra. MERC Global's International Journal of Management. Vol. 7, Issue 2, pp. 127-131.

- Rani, B. Saroja; Satyanarayana, P. V. V. and Kumar, P. Vijaya (2019). The Role of Port Performance in Gateway Logistics and Supply Chain Management. MERC Global's International Journal of Management, Vol. 7, Special Issue 1, pp. 47-54.

- S.P. Sarmah, D.Acharya and S.K.Goyal (2007). Coordination and profit sharing between a manufacturer and a buyer with target profit under credit option. European Journal of Operational Research, 182, pp. 1469-1478.

- Sabbaghi, M. M. (2020). A Supplier Selection Model Emphasizing the Project Risk Management in Drug Production in Pharmaceutical Industry. Tehnički glasnik, 14(2), 111-120.

- Thani Jambulingam, Ravi Kathuria (2020) Antecedents to Buyer-Supplier Coordination in the pharma supply chain. International Journal Of Pharmaceutical and Healthcare Marketing, 08-2019-0058. 